\title{
Apparent Specific Volume of Polystyrene in Benzene, Toluene, Ethylbenzene, and 2-Butanone*
}

\author{
Maurice Griffel, ${ }^{1}$ Ralph S. Jessup, Joseph A. Cogliano, ${ }^{2}$ and Rita P. Park
}

\begin{abstract}
Measurements have been made at temperatures near $27^{\circ}$ and $30^{\circ} \mathrm{C}$ of the densities of purified benzene, toluene, ethylbenzene, and 2-butanone (methylethylketone), and of solutions of a purified sample of polystyrene in these solvents. Within the precision of the measurements (about 1 or 2 in $10^{5}$ density) the apparent specific volume of the polystyrene is a constant independent of the concentration in any one solvent, but depends to some extent upon the solvent. The lowest values, which were obtained with 2-butanone, are about 1 percent lower than the highest values, which were obtained with ethylbenzene. The values are all lower than those of the virtual liquid polymer, obtained by extrapolation of data on specific volume above the glass transition temperature, although the data of other observers indicate that this is not true for all solvents. In all four solvents the change of the apparent specific volume with temperature is less than for the liquid polymer.

The changes in volume upon mixing of polystyrene with the solvents are shown to have a significant effect on such thermodynamic properties as heat, free energy, and entropy of mixing.
\end{abstract}

\section{Introduction}

Theoretical treatments of the thermodynamics of polymer solutions are usually based on assumptions that imply that there is no volume change on mixing of polymers and solvents. Experimentally, however, it is found that there is a small but measurable change in volme when mixing takes place at constant pressure $[1,2,3,4,11,12,15] .^{3}$ Because a change in volume will affect the experimentally determined values of such thermodynamic quantities as heat, free energy, and entropy of mixing at constant pressure [5], a knowledge of the magnitude of the change in volume is of importance in comparing experimental results with theoretical predictions. The work described in this paper was undertaken to provide data to aid in interpreting the results of measurements of heats of mixing of polymers and solvents.

\section{Materials}

The polystyrene used was obtained from the Dow Chemical Co. through the courtesy of R. F. Boyer. It had been prepared by thermal polymerization without catalyst at $180^{\circ} \mathrm{C}$. After receipt of the material it was purified as follows: $150 \mathrm{~g}$ of polystyrene was dissolved in about $750 \mathrm{ml}$ of benzene, and was then precipitated by pouring the solution slowly into about 3 liters of well-stirred methanol. After allowing the precipitate to settle, the liquid was decanted. This procedure was repeated twice. The polystyrene was then dissolved in 2 liters of benzene, the mixture was frozen at $-30^{\circ} \mathrm{C}$. and most of the benzene was removed by evacuation at temperatures not exceeding $3^{\circ} \mathrm{C}$. Evacuation was continued at a

\footnotetext{
*This work was supported in part by the Reconstruction Finance Corporation, Office of Synthetic Rubber, in connection with the Government Synthetic Rubber Program.

1 Present address, The Johns Hopkins University, Baltimore, Md.

2 Present address, George Washington University, Washington, D. C.

3 Figures in brackets indicate the literature references at the end of this paper.
}

temperature of $70^{\circ} \mathrm{C}$ for about 10 days. The temperature was then gradually increased to $120^{\circ} \mathrm{C}$ over a period of about a week, and the pressure over the material was maintained at less than $10^{-4}$ mm of mercury. As a result of this treatment, the polystyrene was fused into a solid mass. To facilitate subsequent handling, it was ground in a cutting mill, so that the final product consisted of particles about $3 \mathrm{~mm}$ or less in diameter.

From observations of light scattering the values $M=190,000$ and $B=5.2 \times 10^{-4} \mathrm{cgs}$ unit were obtained for weight average molecular weight and second virial coefficient, respectively, for the purified polymer. ${ }^{4}$

The volatile constituents of the purified polymer were determined ${ }^{5}$ by heating a crushed sample to $150^{\circ}$ to $160^{\circ} \mathrm{C}$ for $2 \mathrm{hr}$ in a previously evacuated space of known volume, measuring the resulting increase in pressure, and making a mass spectrometric analysis of the gas evolved. The amounts of volatile constituents found in this way, expressed in percentage of the total weight of polymer, are as follows:

\begin{tabular}{|c|c|}
\hline Constituent & $\begin{array}{c}\text { Percentage } \\
\text { by weight }\end{array}$ \\
\hline $\begin{array}{l}\text { Water } \\
\text { Carbon dioxide } \\
\text { Benzene } \ldots\end{array}$ & $\begin{array}{r}0.101 \\
.021 \\
.014\end{array}$ \\
\hline Total volatile impurities ......... & 0. 136 \\
\hline
\end{tabular}

The fact that appreciable amounts of volatile impurities remained after prolonged heating and evacuation, as described above, is in accord with the findings of Grassie [10] in regard to the difficulty of removing volatile impurities from polymers.

${ }_{4}$ These values were obtained by $M$. Wales of the Polymer Structure Section of the Bureau.

${ }^{5}$ In the Mass Spectrometry Section of the Bureau. 
The benzene used was purified ${ }^{6}$ by fractional freezing. The other solvents were purified by distillation. Freezing-curve measurements ${ }^{7}$ indicated a purity of 99.65 and 99.80 mole percent for the toluene and 2-butanone, respectively. The other solvents are believed to be of comparable purity, although no actual determinations of their purity were made. Although impurities in the solvents would affect the densities of both solvents and solutions, it seems very improbable that they would affect the apparent specific volume of the solute to an appreciable extent in view of the small differences between the values for apparent specific volume in different solvents. In table 1 the observed densities of the three hydrocarbon solvents are compared with "best" values of these properties derived from data reported in the literature [6].

TABLE 1. Densities of hydrocarbon solvents

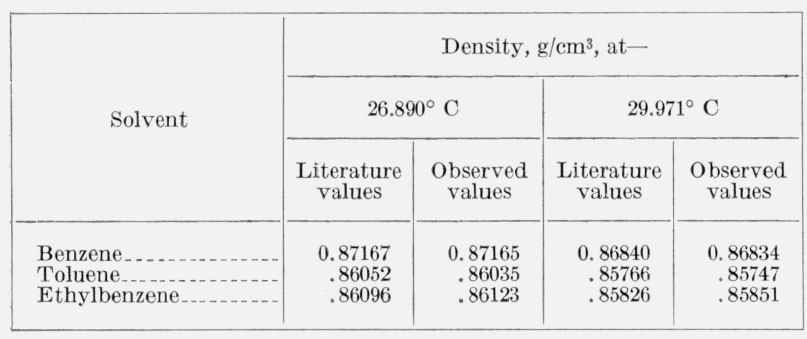

\section{Apparatus and Method}

Densities of solvents and solutions of known composition were measured by means of picnometers, and values of apparent specific volume of polystyrene were calculated from the data.

The Pyrex picnometers used (A, fig. 1) are of the bicapillary type described by Heller and Thompson [1]. The capillaries were of "precision-bore" quality, and before sealing to the picnometers they were calibrated by measuring at $1 / 4$-in. intervals the length of a weighed mercury thread. They were found to have a uniform radius of $0.494 \mathrm{~mm}$ :

The completed picnometers had volumes of about $22 \mathrm{~cm}^{3}$ and were calibrated by weighing when empty and when filled with double-distilled water [14] at temperatures near $27^{\circ}$ and $30^{\circ} \mathrm{C}$. The values for the density of water were calculated from an equation derived by Tilton and Taylor [7] to represent the data of Chappuis [8]. Weighings were made to 0.1 $\mathrm{mg}$ or better on an Ainsworth semimicrobalance, using newly calibrated weights. Final weighings were made after allowing ample time for the attainment of temperature equilibrium in the balance. Two picnometers were used in the measurements, and a third was used as a tare in weighing. All weights were corrected for air buoyancy on the basis of observations of barometric pressure, temperature in the balance case, and relative humidity.

${ }^{6}$ By T. M. Mears of the Engine Fuels Section of the Bureau.

${ }_{7}$ By G. T. Furukawa of the Thermodynamies Section of the Bureau.
The positions of the two menisci relative to reference marks on the capillaries were read to $0.01 \mathrm{~mm}$ by means of a Gaertner traveling microscope. During these readings the picnometers were immersed in a water bath whose temperature during an experiment was maintained constant within about 0.002 $\operatorname{deg} \mathrm{C}$. The wall of the bath through which the menisci were observed was of plate glass. The temperature of the bath was measured by means of a strain-free platinum resistance thermometer and a special Mueller bridge.

The solutions were made up in $60 \mathrm{ml}$ bottles with ground-glass stoppers as follows: A clean bottle containing a Pyrex-glass sealed stirring rod for use with a magnetic stirrer was weighed with its stopper, using a similar bottle for a tare. A sample of polystyrene of approximately known weight was then introduced into the bottle through a funnel in such a manner as to avoid getting any polystyrene on the ground-glass joint, and the bottle was again weighed. A measured amount (usually $50 \mathrm{ml}$ ) of solvent was introduced into the bottle, which was then closed with the ground-glass stopper. In handling the bottle great care was taken to avoid getting any solution on the ground-glass joint. The bottle was then placed on the magnetic stirrer, and stirring was continued until a uniform solution was obtained. When mixing was complete some solvent had condensed in the upper part of the bottle, in the ground-glass joint, and the inside of the stopper. This condensed solvent was removed by drawing clean dry air over these areas, and the stopper was replaced. The two empty picnometers were then weighed; following this, the bottle containing the solution was weighed, and the solution was transferred to the picnometers as described in the following paragraph.

The apparatus shown in figure 1 was used for transferring the solution to the picnometers with a minimum loss of solvent by evaporation. This apparatus consisted of the "wash-bottle" connections with a male standard-taper joint that replaced the stopper in the bottle containing the solution, and with a 22-gage hypodermic needle attached as shown. The solution was forced through the hypodermic needle into the picnometer by introducing helium into the wash bottle through the dryer (C), fig. 1) under a pressure of 2 to $10 \mathrm{lb} / \mathrm{in}^{2}$. Rubber bands were used to hold the joints together. When the picnometer was almost filled the valve controlling the helium supply was closed, and the pressure was released by opening a pincheock (not shown in fig. 1). The hypodermic needle was then disconnected from the filling apparatus and removed from the picnometer.

The ground-glass caps (D, fig. 1) were then put on and the picnometers were inverted and rotated so as to entrap a large bubble in the bulb and thereby remove small bubbles adhering to the wall. The removal of bubbles was found to be more difficult with solutions of high polystyrene content because of the high viscosity of such solutions, and for this reason, the mass fraction of polystyrene in the solutions was not carried above 0.1 . 


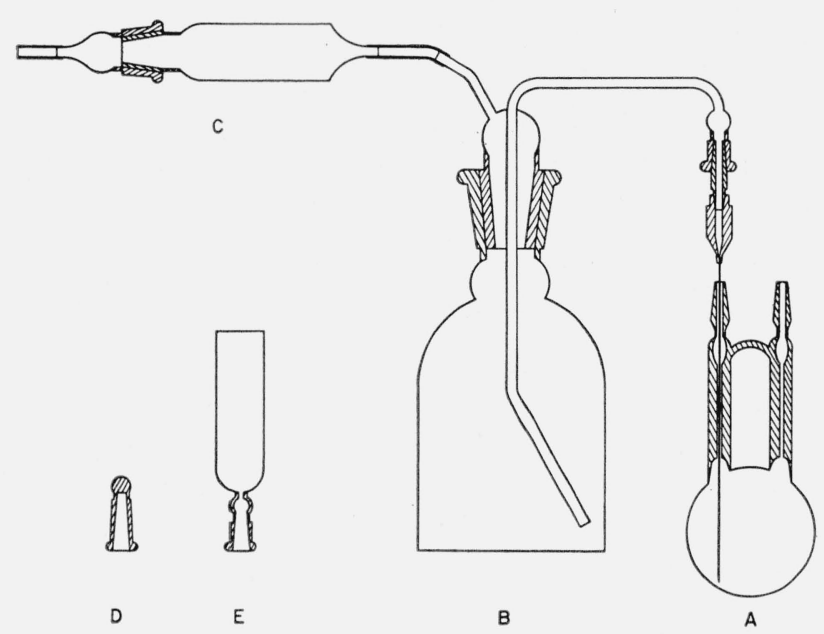

Figure 1. Apparatus used in filling picnometers.

A, Picnometer; B, bottle in which solutions were made up, with "wash-bottle" connections; $\mathrm{C}$, tube containing drying agent to remove water from helium ga used to force solution from bottle, B, to picnometer; D, ground-glass cap for picnometer when being weighed; E, cap containing drying agent and cotton wet with solvent for use when picnometer was in water bath.

After the removal of air bubbles from the solution, the picnometers were placed in an upright position, any liquid entrapped in the capillaries was removed with a hypodermic syringe with a 27 -gage needle, and the menisci were adjusted approximately to the proper height by means of the syringe. The picnometers were then placed in a holder and immersed in the thermostated bath to a point a little below the ground-glass joints, and final adjustment of the height of the menisci was made. Any solution adhering to the capillaries above the menisci was removed with a linen thread. While in the bath the drying tubes (E, fig. 1) containing calcium chloride were attached to the capillaries. A wad of cotton in the bottom of each drying tube was wet with a small amount of solvent to inhibit evaporation from the solution in the picnometer.

After sufficient time had elapsed for the attainment of thermal equilibrium the heights of the menisci relative to the reference marks on the capillary were observed by means of the traveling microscope. The picnometers were then removed from the bath, the drying tubes were replaced with the caps (D, fig. 1), and the picnometers were weighed after allowing sufficient time for the attainment of thermal equilibrium in the balance case.

\section{Results}

Observed values of density of solvents and solutions are given in table 2 , together with values of apparent specific volume of polystyrene calculated

TABLE 2. Experimental values of density and apparent specific volume, and values of density calculated from empirical equations of the form. (1)

\begin{tabular}{|c|c|c|c|c|c|c|c|c|}
\hline \multirow{3}{*}{$\begin{array}{l}\text { Mass frac- } \\
\text { tion poly- } \\
\text { styrene }\end{array}$} & \multicolumn{6}{|c|}{ Density, $\mathrm{g} / \mathrm{cm}^{3}$, at - } & \multirow{2}{*}{\multicolumn{2}{|c|}{$\begin{array}{l}\text { Observed, apparent } \\
\text { specific volume of } \\
\text { polystyrene at- }\end{array}$}} \\
\hline & \multicolumn{3}{|c|}{$26.890^{\circ} \mathrm{C}$} & \multicolumn{3}{|c|}{$29.971^{\circ} \mathrm{C}$} & & \\
\hline & Observed & Calculated & $\begin{array}{l}\text { Observed-- } \\
\text { calculated }\end{array}$ & Observed & Calculated & $\begin{array}{l}\text { Observed- } \\
\text { calculated }\end{array}$ & $26.890^{\circ} \mathrm{C}$ & $29.971^{\circ} \mathrm{C}$ \\
\hline \multicolumn{9}{|c|}{ BENZENE } \\
\hline $\begin{array}{l}0 \\
0 \\
0.019988 \\
.050127 \\
.100008\end{array}$ & $\begin{array}{r}0.871653 \\
.871655 \\
.875122 \\
.880418 \\
.889310\end{array}$ & $\begin{array}{l}0871653 \\
.871653 \\
.875126 \\
.880415 \\
.889311\end{array}$ & $\begin{array}{l}0 \times 10^{-6} \\
+2 \\
-4 \\
+3 \\
-1\end{array}$ & $\begin{array}{l}0.868342 \\
.868346 \\
.871852 \\
.877204 \\
.886143\end{array}$ & $\begin{array}{r}0.868350 \\
.868350 \\
.871850 \\
.877183 \\
.886153\end{array}$ & $\begin{array}{l}-8 \times 10^{-6} \\
-4 \\
+2 \\
+21 \\
-10\end{array}$ & $\begin{array}{l}0.9197_{5} \\
.9194 \\
.9195\end{array}$ & $\begin{array}{r}0.9198 \\
.9196 \\
.9203\end{array}$ \\
\hline \multicolumn{9}{|c|}{ TOLUENE } \\
\hline $\begin{array}{l}0 \\
0 \\
0.005016 \\
.009973 \\
.015046 \\
.020057 \\
.040027 \\
.100195\end{array}$ & $\begin{array}{c}0.860345 \\
.860350 \\
.861253 \\
.8621525 \\
.863066_{5} \\
.863980 \\
.867617 \\
.878758\end{array}$ & $\begin{array}{c}0.860351_{5} \\
.860351_{5} \\
.861255 \\
.862149 \\
.863067 \\
.863975 \\
867613 \\
.878761\end{array}$ & $\begin{array}{l}-7 \times 10^{-6} \\
-2 \\
-2 \\
+3 \\
0 \\
+5 \\
+4 \\
-3\end{array}$ & $\begin{array}{l}0.857467 \\
.857471 \\
.858383_{5} \\
.859281 \\
.860202 \\
.861117_{5} \\
.864771_{5} \\
.875963\end{array}$ & $\begin{array}{r}0.857474 \\
.857474 \\
.858381 \\
.859280 \\
.860201 \\
.861113 \\
.864767 \\
.875963\end{array}$ & $\begin{array}{l}-7 \times 10^{-6} \\
-3 \\
+2 \\
+1 \\
+1 \\
+4 \\
+4 \\
-3\end{array}$ & $\begin{array}{l}0.9187 \\
.9183 \\
.9189_{5} \\
.9187 \\
.9190 \\
.9193\end{array}$ & $\begin{array}{r}0.9185 \\
.9196 \\
.9200 \\
.9199 \\
.9202 \\
.9205\end{array}$ \\
\hline \multicolumn{9}{|c|}{ ETHYLBENZENE } \\
\hline $\begin{array}{l}0 \\
0 \\
0.020076 \\
.050028 \\
.100118\end{array}$ & $\begin{array}{l}0.861225 \\
.861226 \\
.864816 \\
.870222 \\
879386\end{array}$ & $\begin{array}{l}0.861230 \\
.861230 \\
.864812 \\
.870211 \\
.879392\end{array}$ & $\begin{array}{l}-5 \times 10^{-6} \\
-4 \\
+4 \\
+11 \\
-6\end{array}$ & $\begin{array}{l}0.858512 \\
.858515 \\
.862136 \\
.867538 \\
.876753\end{array}$ & $\begin{array}{l}0.858521 \\
.858521 \\
.862117 \\
.867538 \\
.876757\end{array}$ & $\begin{array}{l}-9 \times 10^{-6} \\
-6 \\
+19 \\
0 \\
-4\end{array}$ & $\begin{array}{l}0.9210 \\
.9212 \\
.9216\end{array}$ & $\begin{array}{r}0.9210 \\
.9226 \\
.9228\end{array}$ \\
\hline \multicolumn{9}{|c|}{ 2-RUTANONE } \\
\hline $\begin{array}{l}0 \\
0 \\
0.020128 \\
.050108 \\
.100312\end{array}$ & $\begin{array}{l}0.798850 \\
.798843 \\
.803243 \\
.809949 \\
.821288\end{array}$ & $\begin{array}{l}0.798851 \\
.798851 \\
.803257 \\
.809911 \\
.821304\end{array}$ & $\begin{array}{l}-1 \times 10^{-6} \\
-8 \\
-14 \\
+38 \\
-16\end{array}$ & $\begin{array}{l}0.795575 \\
.795584 \\
.800022 \\
.806738 \\
.818160\end{array}$ & $\begin{array}{r}0.795587 \\
.795587 \\
.800019 \\
.806711 \\
.818173\end{array}$ & $\begin{array}{l}-12 \times 10^{-6} \\
-3 \\
+3 \\
+27 \\
-13\end{array}$ & $\begin{array}{l}0.9114 \\
.9093 \\
.9108\end{array}$ & $\begin{array}{r}0.9102 \\
.9100 \\
.9111\end{array}$ \\
\hline
\end{tabular}


TABLE 3. Values of the constants $\rho_{1}$ and $\varphi_{2}$ in equation (1)

\begin{tabular}{|c|c|c|c|c|c|c|c|c|}
\hline \multirow{2}{*}{ Solvent } & \multicolumn{2}{|c|}{$26.890^{\circ} \mathrm{C}$} & \multicolumn{2}{|c|}{$27.000^{\circ} \mathrm{C}$} & \multicolumn{2}{|c|}{$29.971^{\circ} \mathrm{C}$} & \multicolumn{2}{|c|}{$30.000^{\circ} \mathrm{C}$} \\
\hline & $\rho_{1}$ & $\varphi_{2}$ & $\rho_{1}$ & $\varphi_{2}$ & $\rho_{1}$ & $\varphi_{2}$ & $\rho_{1}$ & $\varphi_{2}$ \\
\hline $\begin{array}{l}\text { Benzene } \\
\text { Toluene } \\
\text { Ethylbenzene. } \\
\text { 2-Butanone... }\end{array}$ & $\begin{array}{l}\mathrm{g} / \mathrm{cm}^{3} \\
0.871653 \\
.8603515 \\
.861230 \\
.798851\end{array}$ & $\begin{array}{r}c m^{3} / g \\
091947 \\
.91929 \\
.92160 \\
.91065\end{array}$ & $\begin{array}{l}\mathrm{g} / \mathrm{cm} \mathrm{m}^{3} \\
0.871535 \\
.860249 \\
.861133 \\
.798734\end{array}$ & $\begin{array}{r}c m^{3} / g \\
0.91950 \\
.91933 \\
.92164 \\
.91066\end{array}$ & $\begin{aligned} g / c m^{3} \\
0.868350 \\
.857474 \\
.858521 \\
.795587\end{aligned}$ & $\begin{array}{r}\mathrm{cm}^{3} / \mathrm{g} \\
0.92026 \\
.92050 \\
.92281 \\
.91103\end{array}$ & $\begin{array}{c}\mathrm{g} / \mathrm{cm}^{3} \\
0.868319 \\
.857447 \\
.858496 \\
.795556\end{array}$ & $\begin{array}{r}\mathrm{cm}^{3} / \mathrm{g} \\
0.92027 \\
.92051 \\
.92282 \\
.91103\end{array}$ \\
\hline
\end{tabular}

therefrom, and with values of density calculated from empirical equations of the form

$$
\rho=\frac{\rho_{1}}{1-w_{2}\left(1-\rho_{1} \varphi_{2}\right)},
$$

where $w_{2}$ is the mass fraction of polystyrene in the solution, $\rho$ is the density of the solution, and $\rho_{1}$ and $\varphi_{2}$ are constants at a given temperature. This equation was derived from the definition of apparent specific volume on the assumption that this quantity is independent of composition of the solution and is equal to $\varphi_{2}$. Values of the constants $\rho_{1}$ and $\varphi_{2}$ were determined by the method of least squares from the experimental values of $\rho$ and $w_{2}$ and are given in table 3 . The values of $\varphi_{2}$ may be compared with the experimental values of apparent specific volume given in table 2 .

It may be noted that eq (1) implies that density can also be represented by an equation of the form

$$
\rho=\rho_{1}+A c_{2},
$$

where $c_{2}$ is the concentration of polymer in grams of polymer per cubic centimeter of solution, and where

$$
A=\left(1-\rho_{1} \varphi_{2}\right) .
$$

Table 2 shows that the agreement between the observed and calculated densities is within 1 or $2 \times 10^{-5}$, except in the case of solutions in 2-butanone, where the maximum difference is $4 \times 10^{-5}$. The results on 2-butanone solutions are less reliable than the others because of the difficulty of avoiding some absorption of water in handling. It is believed that the agreement between experimental and calculated densities is within the accuracy of the measurements. This substantiates the assumption made in deriving eq (1) that within the accuracy of the data the apparent specific volume of polystyrene is independent of the composition of the solutions over the composition range covered. This means, of course, that in this range the partial specific volume of the solute is constant and equal to the apparent specific volume, and that the partial specific volume of the solvent is constant and equal to the specific volume of the pure solvent.

\section{Comparison With Previous Measurements}

Values of apparent specific volume of polystyrene obtained in the present work are compared in figure 2 with values for the apparent specific volume in chlorobenzene and bromobenzene by Heller and Thompson [1], in benzene by Danes [11], in toluene by Boyer and Spencer [4], and in various solvents by Streeter and Boyer [15]. The values attributed to Boyer and Spencer were calculated from the density data given in reference [4]. They are somewhat higher than the values of partial specific volume attributed to Boyer and Spencer by Spencer and Gilmore [12]. Streeter and Boyer reported densities of solutions of various concentrations, expressed in grams of polymer per unit volume of solution, and values of partial specific volume calculated from these data. The value of partial specific volume in each solvent was calculated from two experimental points that lie exactly on a straight line drawn to represent density as a function of concentration. The two points used for this purpose were taken in the lowconcentration range, except where there were seeming discrepancies in the data.

As stated previously, a linear relation between density and concentration (eq 2) implies that the partial specific volume is constant and equal to the apparent specific volume, which is related to the constants $A$ and $\rho_{1}$ in eq (2) by $\varphi_{2}=(1-A) / \rho_{1}$. The use of points in the low-concentration range to determine the slope $A$ is undesirable because, if the slope is constant, it can be determined more accurately by making use of the data over the entire concentration range. The present writers have found that, except for solutions in one solvent as noted later, the density data of Streeter and Boyer can be represented within 1 or $2 \times 10^{-4}$ by equations of the form (2), with the constants $\rho_{1}$ and $A$ determined by the method of least squares. There is no indication of a systematic trend in the deviations of experimental densities from such equations, so that within the accuracy of the measurements, the data of Streeter and Boyer indicate that $\varphi_{2}$ is a constant independent of concentration for each of the solvents (with the exception of the one referred to previously). For this reason, it seems preferable to calculate the values of $\varphi_{2}$ from the values of $\rho_{1}$ and $A$ determined from all the data on each solvent by the method of least squares, and the values shown in figure 2 were obtained in this way.

The density data of Streeter and Boyer on solutions in o-dichlorobenzene depart from a straight line (eq 2) in a systematic manner by amounts that appear to be considerably in excess of the uncertainty of the data. Values of $\varphi_{2}$ calculated from experimental values of density by means of eq (1) can be represented graphically with a precision corre- 
sponding to about $1 \times 10^{-4}$ in density by a curve that is horizontal for values of concentration from 6 to 12 $\mathrm{g} / 100 \mathrm{ml}$ of solution, but which rises at lower concentrations and approaches a value of about $\varphi_{2}=1.0$ at zero concentration. The value for o-dichlorobenzene attributed to Streeter and Boyer in figure 2 was taken from the horizontal part of this curve.

Data not shown in figure 2 include a value $\varphi_{2}=$ 0.877 at $25^{\circ} \mathrm{C}$ derived from the data of Streeter and Boyer on solutions in chloroform; values of $\varphi_{2}$ in various solvents ranging from 0.88 to 0.93 at $20^{\circ} \mathrm{C}$ with uncertainties of \pm 0.01 to \pm 0.04 reported by Signer and Gross [2]; and the values, all at $20^{\circ} \mathrm{C}$, $\varphi_{2}=0.939$ in benzene, 0.945 in 2-butanone, 0.953 in cyclohexane, and 0.889 in chloroform derived from data reported by Breitenbach and Frank [3] on the change in volume accompanying swelling of a crosslinked polystyrene containing 0.12 percent of divinylbenzene. It is possible, of course, that these latter values are not comparable with values of $\varphi_{2}$ derived from densities of solutions of polystyrene.

The straight line near the top of figure 2 represents an extrapolation of the linear equation given by Fox and Flory [9] for the specific volume of polystyrene of infinite molecular weight above the glass transition

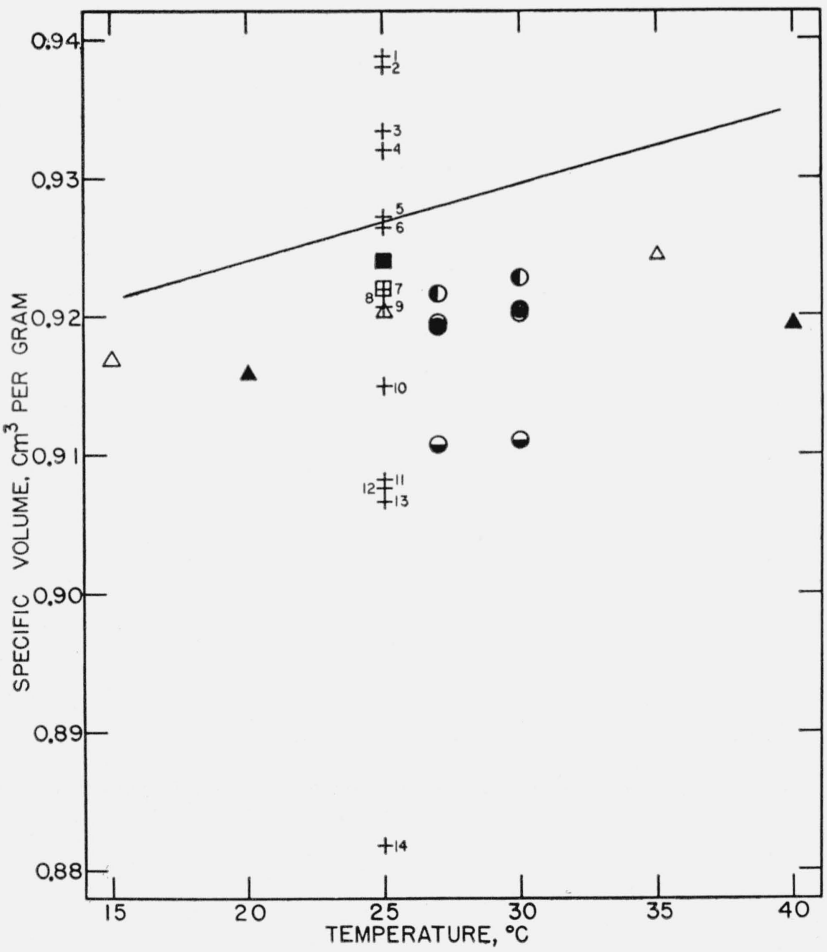

FIGURE 2. A pparent specific volume of polystyrene in various solvents.

Heller and Thompson, bromobenzene; $\square$, Heller and Thompson, chloroDenes, benzene; B Boyer and Spencer, toluene; + Streeter and Benzene, $\triangle$, Danes, benzen, $\mathbf{A}$, Boyer and spencer, toluene; + , streeter and Boyer, various solvents as follows: (1) Decalin; (2) (7) ben (1) o-dichlorobenzene; (5) $x$ dilo rm; (12) 2-butanone; (13) 2-heptanone; (14) tetralin.

The circles represent results of present work as follows; $\bigcirc$, Benzene; ene; 0 , ethylbenzene; $\bullet$, 2-butanone.

The straight line near the top of the figure is an extrapolation of Fox and Flory's equation for the specific volume of polystyrene of infinite molecular weight above the glass-transition temperature. temperature, and may be regarded as representing the specific volume to be expected of bulk polystyrene if it could be obtained as a liquid at room temperature [1]. It is seen that most of the values of apparent specific volume in solution lie below this line, and that all the data indicate that the coefficient of expansion of dissolved polystyrene is somewhat smaller than that of the virtual bulk liquid. This is true also if we include the data of Danes over the temperature range from $15^{\circ}$ to $65^{\circ} \mathrm{C}$, and the data of Boyer and Spencer from $0^{\circ}$ to $40^{\circ} \mathrm{C}$.

\section{Effect of Changes in Volume Upon Thermodynamic Properties}

If we take the value $0.949_{8} \mathrm{~cm}^{3} / \mathrm{g}$ calculated from the equation given by Fox and Flory [9] for the specific volume of solid polystyrene at $27^{\circ} \mathrm{C}$, it will be seen that, according to the data given in table 3 , the change in volume, $\left(\Delta V=\varphi_{2}-0.949_{8}\right)$, when $1 \mathrm{~g}$ of solid polystyrene is dissolved at $27^{\circ}$ will have the following values for the various solvents:

\begin{tabular}{|c|c|}
\hline \multicolumn{1}{c|}{ Solvent } & $\Delta V\left(27^{\circ} \mathrm{C}\right)$ \\
\hline & $\mathrm{cm}^{3} / g$ polystyrene \\
Benzene & $-0.030_{3}$ \\
Toluene & $-.030_{5}$ \\
Ethylbenzene & $-.028_{2}$ \\
2-Butanone & $-.039_{1}$ \\
\hline
\end{tabular}

It is of interest to consider the effect of such changes in volume upon thermodynamic properties of polystyrene solutions. ${ }^{8}$ If polymer and solvent are initially at atmospheric pressure and if mixing is supposed to take place at constant volume, and then a change in volume, $\Delta V$, is allowed to take place to bring the pressure back to atmospheric, the change in any thermodynamic quantity, $G$, due to the change in volume will be given by

$$
\Delta G=\left(\frac{\partial G}{\partial V}\right)_{T} \Delta V
$$

For example, we obtain from well-known thermodynamic relations

$$
\begin{aligned}
& \Delta H=\frac{T \alpha-1}{\beta} \Delta V, \\
& \Delta U \cong \frac{T \alpha}{\beta} \Delta V, \\
& \Delta S=\frac{\alpha}{\beta} \Delta V, \\
& \Delta F=-\frac{1}{\beta} \Delta V,
\end{aligned}
$$

${ }^{8}$ Similar calculations have been made for various liquid mixtures by Scatchard, Wood, and Mochel [16] and by Wood and Gray [17]. 
where $\alpha$ and $\beta$ are coefficients of expansion and compressibility, respectively. For an infinitely dilute solution in benzene at $27^{\circ} \mathrm{C}$ we obtain $\alpha=1.232 \times 10^{-3}\left({ }^{\circ} \mathrm{C}\right)^{-1}$ from the data of table 2 , and from International Critical Tables [13], $\beta=1.00 \times 10^{-4}$ bar $^{-1}$, so that at $27^{\circ} \mathrm{C}\left(=300^{\circ} \mathrm{K}\right)$

$$
\left(\frac{\partial H}{\partial V}\right)_{T}=-630 j / \mathrm{cm}^{3},
$$

and for the change in volume of $-0.0303 \mathrm{~cm}^{3}$ upon solution of $1 \mathrm{~g}$ of solid polystyrene in benzene $\Delta H=19.1 j=4.6$ cal. Similarly, we obtain for the effect of volume change due to solution of $1 \mathrm{~g}$ of polystyrene in benzene at $27^{\circ} \mathrm{C} \Delta U=-2.7 \mathrm{cal}$, $\Delta S=-0.0089 \mathrm{cal} /{ }^{\circ} \mathrm{C}, \Delta F=7.2 \mathrm{cal}$. The values for $\Delta U$ and $\Delta H$ resulting from volume change upon mixing may be compared with a preliminary experimental value of approximately -6 cal for the heat of mixing of $1 \mathrm{~g}$ of polystyrene with toluene.

In a similar manner, taking the volume of the liquid polymer at $27^{\circ} \mathrm{C}$ as $0.927_{9}$ [9], the changes in the thermodynamic functions due to change in volume on mixing $1 \mathrm{~g}$ of liquid polystyrene with benzene to form an infinitely dilute solution are calculated to be $\Delta H=+1.3$ cal, $\Delta U=-0.7_{5}$ cal, $\Delta S=-0.0025 \mathrm{cal} /{ }^{\circ} \mathrm{C}, \Delta F=+2.0_{5}$ cal.

According to Heller and Thompson [1] only the change in volume upon solution of liquid polystyrene, and therefore only the changes in the functions $H, U$, etc., calculated from this change in volume have thermodynamic significance, because of the fact that the solid polymer is not in a state of thermodynamic equilibrium. It will be seen that even in the case of the liquid polystyrene there is a significant change in the thermodynamic functions as a result of change in volume upon mixing with solvent.

As stated previously constancy of the apparent specific volume implies that the partial specific volume of the solvent is equal to the actual specific volume of the pure solvent. There is then no change in volume due to dilution and no effect of change in volume upon partial thermodynamic quantities, such as $\Delta \overline{\mathrm{H}}_{1}, \Delta \overline{\mathrm{S}}_{1}, \Delta \overline{\mathrm{F}}_{1}$, etc., within the composition range covered.

It should be emphasized that the results reported in this paper are for unfractionated polystyrene of unknown molecular-weight distribution, which contained the amounts of impurities given previously. There appears to be no satisfactory method of reducing the results to the basis of pure polystyrene. The results may depend to some extent upon the molecular-weight distribution in the polymer. This problem has been discussed by Heller and Thompson [1] on the basis of certain assumptions regarding the relation between the specific volume of the virtual liquid polymer (which is known to depend upon molecular weight [9]) and the apparent specific volume in solution. If it is assumed that the number-average molecular weight of the polystyrene used in the present measurements is one-half of the weight-average and that the molecular weight distribution functions is that given by Lansing and Kraemer [18], then the treatment of Heller and Thompson [1] indicates that the measured apparent specific volume does not differ appreciably from that of a polystyrene having a uniform molecular weight of about 100,000 .

\section{Summary and Conclusions}

Values are reported for the densities of purified benzene, toluene, ethylbenzene, and 2-butanone, and of solutions of polystyrene in these solvents at temperatures near $27^{\circ}$ and $30^{\circ}$ C. Within the accuracy of the measurements, values of apparent specific volume of polystyrene derived from the data are independent of composition of the solutions in the range 0.5 to 10 percent of polystyrene by weight.

The results confirm the conclusion of Heller and Thompson [1] that the apparent specific volume of polystyrene depends upon the solvent. This is also shown very strikingly by the results of Streeter and Boyer [15].

The changes in volume upon mixing of polystyrene with solvent are shown to have a significant effect on the thermodynamic properties of the solution.

\section{References}

[1] W. Heller and A. C. Thompson, J. Colloid Sci. 6, 57 (1951).

[2] R. Signer and R. Gross, Helv. Chim. Acta 17, 59 (1934).

[3] J. W. Breitenbach and H. P. Frank, Monatsh. 99,531 (1948)

[4] R. F. Poyer and R. S. Spencer, J. Polymer Sci. 3, 97 (1948).

[5] J. H. Hildebrand and R. L. Scott, Solubility of nonelectrolytes (Reinhold Publishing Corporation, New York, N. Y., 1950)

[6] Selected values of the properties of hydrocarbons, American Petroleum Institute Research Project 44, at the Carnegie Institute of Technology, table 5a (Oct. 31, 1950).

[7] L. W. Tilton and J. K. Taylor, J. Research NBS 18, 205 (1937) RP971.

[8] P. Chappuis, Bureau international des Poids et Mesures, Travaux et Memoires 13 (1907).

[9] T. G. Fox Jr, and P. J. Flory, J. Appl. Phys. 21, 581 (1950).

[10] N. Grassie, J. Polymer Sci. 6, 643 (1951).

[11] V. Z. Danes, Kolloid-Z. 68, 110 (1934).

[12] R. S. Spencer and G. D. Gilmore, J. Appl. Phys. 20, 502 (1949).

[13] International Critical Tables, 3, 29 and 39 (McGraw-Hill Book Co., Inc., New York, N. Y., 1928)

[14] N. Bauer, Weissberger's Pbysical methods in organic chemistry, 1, 69 (Interscience Publishers, Inc., New York, N. Y. 1945)

[15] D. J. Streeter and R. F. Boyer, Ind. Eng. Chem. 43, 1790 (1951).

[16] G. Scatchard, S. E. Wood, and J. M. Mochel, J. Phys. Chem. 43, 119 (1939); J. Am. Chem. Soc. 61, 3206 (1939); and J. Am. Chem. Soc. 62, 712 (1940).

[17] S. E. Wood and J. A. Gray, III, J. Am. Chem. Soc. 74, 3729 (1952).

[18] W. D. Lansing and E. O. Kraemer, J. Am. Chem. Soc. 5\%, 1369 (1935).

Washington, November 6, 1953 